\title{
Symptoms versus testing: How should we follow-up achalasia after myotomy?
}

\author{
Victor van Berkel, $\mathrm{MD}, \mathrm{PhD}$
}

\footnotetext{
From the Department of Cardiovascular and Thoracic Surgery, University of Louisville School of Medicine, Louisville, Ky.

Disclosures: Author has nothing to disclose with regard to commercial support.

Received for publication March 30, 2018; accepted for publication April 5, 2018; available ahead of print April $30,2018$.

Address for reprints: Victor van Berkel, MD, PhD, Department of Cardiovascular and Thoracic Surgery, University of Louisville School of Medicine, 201 Abraham Flexner Way, Suite 1200, Louisville, KY 40202 (E-mail: victor.vanberkel@louisville.edu).

J Thorac Cardiovasc Surg 2018;156:869-70

$0022-5223 / \$ 36.00$

Copyright (c) 2018 by The American Association for Thoracic Surgery

https://doi.org/10.1016/j.jtcvs.2018.04.003
}

Achalasia, which results from degeneration of neurons within the esophageal wall, is a frustrating disease. It is not clear why this degeneration occurs, but the end effect is a loss of peristalsis within the esophagus and an impaired relaxation of the lower esophageal sphincter. This loss of relaxation causes a functional obstruction of the esophagus, leading to the dysphagia and regurgitation that are the hallmark symptoms of the disease. ${ }^{1}$ As such, treatment of achalasia focuses on decreasing the resting pressure in the lower esophageal sphincter, either by pharmacologic routes (calcium-channel blockers, nitrates, or injection of botulinum toxin) or by mechanical disruption of the muscle fibers of the lower esophageal sphincter. ${ }^{2}$

Ernst Heller ${ }^{3}$ first described a surgical approach to achalasia in 1914, and the minimally invasive version of this procedure is current standard approach. This operation is quite effective, with effective symptom control reported in approximately $90 \%$ of patients. ${ }^{4,5}$ Unfortunately, although disruption of the lower esophageal sphincter does improve the functional esophageal obstruction, no surgical or pharmacologic treatment can reverse the degeneration of the esophageal neurons. As such, these patients do not have normal swallowing, even after treatment that relieves symptoms.

Nearly 20 years ago, a group from the Cleveland Clinic described the use of timed barium esophagogram (TBE) to assess early outcomes after Heller myotomy. ${ }^{6}$ This involves the use of a relatively large initial bolus of barium (250 mL), followed by upright films at 1, 2, and 5 minutes after ingestion. The height and width of the retained column of barium is then measured on the upright film. Their previous results demonstrated that the height and width of the barium column decreased after myotomy, suggesting an improvement in emptying; interestingly, however, resolution of symptoms did not correlate with the findings on esophagogram.

In this issue of the Journal, Kachala and colleagues, ${ }^{7}$ representing the same Cleveland Clinic group, present their

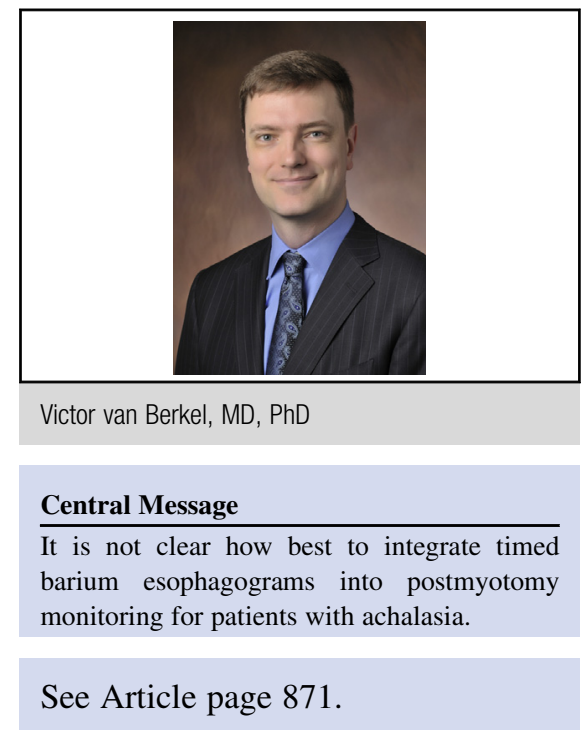

data regarding the use of TBEs in the long-term follow-up of patients after myotomy. In this single-center, retrospective study, patients who had undergone myotomy had TBEs performed 8 weeks after the operation and then yearly thereafter. Kachala and colleagues ${ }^{7}$ found that, in general, the TBE demonstrated improvement in emptying immediately after the operation, and this finding remained stable with time. Patients who had a persistently wide TBE at 1 minute on the postoperative study had a higher likelihood of the need for reintervention. Notably, once again, there was no clear correlation between the TBE results and symptom improvement.

Unfortunately, it is difficult to know the clinical relevance of this study. As someone who performs myotomies, for example, I would be hard pressed to reintervene on a patient with a worsening TBE who is not reporting symptoms. Similarly, if a patient has severe recurrent symptoms but a stable, improved TBE, it is not clear whether we could advise the patient that reintervention would not be beneficial. The data presented do not speak to these circumstances. For a disease process that is driven by symptom management, a test that does not correlate closely with those symptoms has limited utility.

\section{References}

1. Boeckxstaens GE, Zaninotto G, Richter JE. Achalasia. Lancet. 2014;383:83-93. 2. Spiess AE, Kahrilas PJ. Treating achalasia: from whalebone to laparoscope JAMA. 1998;280:638-42. 
3. Heller E. Extra mucous cardioplasty in chronic cardiospasm with dilation of the esophagus. Mitt Grenzgels Med Chir. 1913;27:141.

4. Zaninotto G, Costantini M, Rizzetto C, Zanatta L, Guirroli E, Portale G, et al. Four hundred laparoscopic myotomies for esophageal achalasia: a single centre experience. Ann Surg. 2008;248:986-93.

5. Litle VR. Laparoscopic Heller myotomy for achalasia: a review of the controversies. Ann Thorac Surg. 2008;85:S743-6.
6. Kostic SV, Rice TW, Baker ME, Decamp MM, Murthy SC, Rybicki LA, et al. Timed barium esophagogram: a simple physiologic assessment for achalasia. $J$ Thorac Cardiovasc Surg. 2000;120:935-43.

7. Kachala SS, Rice TW, Baker ME, Rajeswaran J, Thota PN, Murthy SC, et al. Value of routine timed barium esophagram followup in achalasia after myotomy. J Thorac Cardiovasc Surg. 2018;156: 871-7.e2. 